\title{
Eficiência bioeconômica da suplementação de novilhos em pastagens de Capim Marandu
}

\section{Bio-economic efficiency of supplementation for steers in Marandu Grass pasture}

\author{
Daniel Marino Guedes de Carvalho ${ }^{1 *}$; Luciano da Silva Cabral';

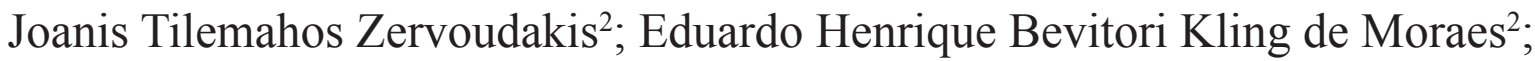 \\ João Marcos Beltrame Benatti ${ }^{3}$; Jefferson Fabiano Werner Koscheck ${ }^{4}$; \\ André Alves de Oliveira ${ }^{4}$
}

\begin{abstract}
Resumo
Objetivou-se avaliar o efeito de suplementos mineral, múltiplo, energético e protéico sobre o desempenho, comportamento de pastejo e custo de produção de bovinos em pastagem de capim Marandu. $\mathrm{O}$ experimento teve duração de 84 dias, conduzido em área experimental constituída por quatro piquetes de 1,45 ha. Foram utilizados 20 novilhos com idade e peso corporal inicial de 10 meses e $172 \mathrm{~kg}$, respectivamente. Usou-se delineamento inteiramente casualizado com quatro tratamentos e cinco repetições. Foi fornecido $1,0 \mathrm{~kg}$ animal $\mathrm{dia}^{-1}$ de suplementos concentrados. Os animais foram pesados no início e final do experimento, para determinação do ganho de peso diário. O ganho de peso dos animais foi de 0,$380 ; 0,600 ; 0,750$ e $0,730 \mathrm{~kg} / \mathrm{dia}$, respectivamente, para os suplementos mineral, energético, múltiplo e protéico verificando-se diferença estatística significativa entre os animais suplementados e que receberam mistura mineral. A suplementação múltipla produziu GMD 49,33\% e $20,00 \%$ superiores os suplementos mineral e energético. Não houve diferença para comportamento de pastejo $(\mathrm{P}>0,05)$. Os animais recebendo mistura mineral tiveram tempo de pastejo de 8,40 horas animal $\mathrm{dia}^{-1}$. O suplemento múltiplo proporcionou melhor desempenho econômico considerando a venda dos animais aos $350 \mathrm{~kg}$ de peso corporal.
\end{abstract}

Palavras-chave: Comportamento, custo de produção, energia, desempenho, proteína, suplementos

\footnotetext{
Abstract

The objective was to evaluate the effect of mineral salt (MS), multiple (MS), energy (ES) and protein supplements (PS) on performance, behavior and production cost of the cattle in Marandu grass pasture. The experiment lasted 84 days, conducted in the experimental area consists of four paddocks of 1.45 ha. Twenty steers were used with age and initial body weight of $172 \mathrm{~kg}$ and 10 months, respectively. It used a completely randomized design with four treatments and five replicate. The energy, multiple and protein supplements was supplied on $1.0 \mathrm{~kg} \mathrm{day}^{-1}$. The

${ }^{1}$ Parte da Tese de Doutorado, Zootecnista, Dr. em Agricultura Tropical, Universidade Federal do Mato Grosso, UFMT, Barra do Garças, MT. E-mail: danielguedes14@yahoo.com.br

${ }^{2}$ Zootecnistas, Drs. em Zootecnia, UFMT, Cuiabá, MT. E-mail: cabralls@ufmt.br; joanisz@yahoo.com.br; edukling@ufmt.br

${ }^{3}$ Zootecnista, Dr. em Zootecnia, Universidade Estadual Paulista "Julio de Mesquita Filho", UNESP, Jaboticabal, SP. E-mail:

${ }^{4}$ Médicos Veterinários, Mestres em Ciência Animal, UFMT, Cuiabá, MT. E-mail: jeffersonfwk@hotmail.com; andrezoo07@
} jonizoo@hotmail.com yahoo.com.br

* Autor para correspondência 
animals were weighed at the beginning and end of the experiment, to determine the average daily gain (ADG). The weight gain of animals was $0.380,0.600,0.750$ and $0.730 \mathrm{~kg} / \mathrm{day}$, respectively, for treatments MS, ES, MS and PS, have been verified statistical difference between supplemented animals and animals than received only mineral salt. The multiple supplement produced ADG $49.33 \%$ and $20.00 \%$ higher than the mineral salt. The multiple and protein supplements permitted average performance $18.92 \%$ higher than the energy supplement. There was no difference in behavior of grazing $(\mathrm{P}>0.05)$. Animals receiving the mineral mixture had time to 8.40 hours of grazing animal day-1. The multiple supplement provided better economic performance considering the sale of animals to $350 \mathrm{~kg}$ body weight.

Key words: Behavior, energy, performance, production cost, protein, supplements

\section{Introdução}

O processo de globalização da economia tem causado grandes mudanças em diversos setores do agronegócio. A produção de gado de corte no Brasil tem sido desafiada a estabelecer sistemas de produção capazes de produzir, de forma eficiente, carne de boa qualidade a baixo preço sendo competitivos, sustentáveis e produzindo animais precoces (EUCLIDES et al., 2001). A baixa produção bovina nos trópicos pode ser atribuída, principalmente, à nutrição inadequada resultante da sazonalidade forrageira (EUCLIDES et al., 1998).

As condições climáticas, nos trópicos, promovem uma ampla variação anual da quantidade e qualidade da forrageira das pastagens, que é a principal causa das idades avançadas de abate (COUTINHO FILHO; JUSTO; PERES, 2005). Vários são os trabalhos demonstrando limitações das Brachiarias em promover altas taxas de ganho de peso no período da seca (EUCLIDES et al., 1998; EUCLIDES et al., 2001; SANTOS et al., 2004).

Segundo Van Soest (1994) o fornecimento de fontes de nitrogênio ou de energia pode ter efeitos diferenciados, dependendo da concentração de nitrogênio da dieta, assim como dos requisitos do animal em relação ao requisito da microbiota ruminal. Assim trabalhando-se com dietas pobres em proteína bruta (PB), como as pastagens na época seca, o requisito da microbiota ruminal é superior àquele do animal, o uso de proteína é desejável, enquanto o uso da energia de rápida fermentação é indesejável.
Em concordância, Costa et al. (2008), simulando uso da suplementação em experimento in vitro, encontraram acréscimos nas taxas de degradação da forragem e diminuição no tempo de retenção ruminal com suplementação protéica. Já quando o suplemento possuía características energéticas a degradação da FDNpd diminuiu e houve aumento da taxa de retenção ruminal, segundo os autores em função da competição por nitrogênio pelas bactérias aminolíticas em ralação as celulolíticas.

Segundo Figueiredo et al. (2007) existem duas formas de interferir no ganho financeiro de uma atividade: aumentando seu preço de venda ou implementando a redução de custos e aumento de produtividade. Questionamentos sobre a viabilidade econômica da suplementação existem a muito tempo, mesmo com vários autores apontando as vantagens da suplementação (PORTO et al., 2009; CARVALHO et al., 2009; PILAU; ROCHA; SANTOS, 2003).

Objetivou-se avaliar o uso de suplementação mineral, energética, protéica e múltipla sobre o desempenho, comportamento animal e custo de produção de bovinos em pastagens de capim marandu na transição seca-águas.

\section{Material e Métodos}

O experimento foi conduzido nas dependências do Setor de Bovinocultura da fazenda experimental da Universidade Federal de Mato Grosso, localizada a 30 km de Cuiabá, no município de Santo Antônio de 
Leverger - MT, na região da Baixada Cuiabana, com início em 28 de Julho e término em 22 de Outubro de 2009, com um total de 84 dias experimentais.

A área destinada aos animais para a avaliação do desempenho foi constituída por quatro piquetes de
1,45 ha cada, formados com a gramínea Brachiaria Brizanta cv. Marandu, providos de bebedouros e cochos cobertos. Os dados meteorológicos do período em que o experimento foi desenvolvido e dos dois meses que antecederam o início do experimento estão dispostos na Tabela 1 .

Tabela 1. Precipitação pluviométrica (PP) e temperaturas máximas (TM), mínimas (TMI) e médias (TMP) durante o período experimental.

\begin{tabular}{lcccc}
\hline \multirow{2}{*}{ Meses } & PP & TM & TMI & TMP \\
\cline { 2 - 5 } & $(\mathrm{mm})$ & & $\left({ }^{\circ} \mathrm{C}\right)$ & 22,75 \\
Junho & 60,50 & 28,70 & 16,80 & 17,40 \\
Julho & 37,60 & 31,50 & 16,40 & 24,45 \\
Agosto & 22,00 & 33,60 & 20,50 & 27,00 \\
Setembro & 77,10 & 33,90 & 19,60 & 25,60 \\
Outubro & 142,30 & 34,60 & \\
\hline
\end{tabular}

Fonte: Estação meteorológica da fazenda experimental da UFMT.

Foram utilizados 20 bezerros não castrados, Nelore e anelorados, com idade e pesos médios iniciais de nove meses e $172 \mathrm{~kg}$, respectivamente, distribuídos aleatoriamente entre os tratamentos, assim constituídos: Mistura mineral (MM): suplemento constituído apenas por mistura mineral (testemunha); Suplemento energético (SE): suplemento constituído de mistura mineral e milho grão moído; Suplemento múltiplo (SM): suplemento constituído de mistura mineral, farelo de soja, milho grão moído e ureia/sulfato de amônio (9:1); Suplemento proteico (SP): suplemento constituído de mistura mineral, farelo de soja e ureia/sulfato de amônio (9:1).
Os animais foram pesados no início e final do experimento após jejum prévio de 16 horas. Os animais foram rotacionados entre os piquetes a cada 14 dias, visando reduzir possíveis variações entre a disponibilidade e qualidade da forragem disponível nos piquetes experimentais. Todos animais foram submetidos ao controle de ecto e endoparasitos no início do experimento. A composição percentual dos suplementos com base na matéria natural encontrase na Tabela 2. Os suplementos foram fornecidos na quantidade de $1,0 \mathrm{~kg}$ /animal diariamente às 10:00 horas, monitorando-se as sobras de suplementos. A mistura mineral que foi fornecida ad libitum com monitoramento do consumo. 
Tabela 2. Composição percentual dos suplementos na matéria natural e custo dos ingredientes.

\begin{tabular}{lcccccc}
\hline \multirow{2}{*}{\multicolumn{1}{c}{ Ingrediente }} & \multicolumn{3}{c}{ Valores $^{2}$} & \multicolumn{3}{c}{ Suplementos } \\
\cline { 2 - 7 } & $\mathrm{R} \$$ /ton & $\mathrm{R} \$ / \mathrm{kg}$ & $\mathrm{MM}$ & $\mathrm{SE}$ & $\mathrm{SM}$ & $\mathrm{SP}$ \\
\hline Farelo de soja & 750,00 & 0,75 & - & - & 10,00 & 95,00 \\
Milho grão moído & 350,00 & 0,35 & - & 95,00 & 80,00 & - \\
Uréia+S.Amônio $(9: 1)^{\text {Mistura mineral }^{1}}$ & $1.800,00$ & 1,80 & - & - & 5,00 & 5,00 \\
\hline
\end{tabular}

${ }^{1}$ Mistura mineral comercial - Níveis de garantia: Cálcio 168g; fósforo 65g; sódio 141,2g; magnésio 5g; enxofre 17,8g; iodo 30mg; ferro 463mg; selênio16,2mg; cobalto 144mg; manganês 500mg; flúor 650mg; cobre $1.295 \mathrm{mg}$; zinco $4.500 \mathrm{mg}$; ${ }^{2}$ Valores praticados no mercado local.

Fonte: Elaboração dos autores.

No primeiro dia de cada período experimental realizou-se a coleta de amostras da forragem nos diferentes piquetes. Para esta amostragem foram realizadas medições da altura da forragem em 100 pontos por piquete, divididos em duas diagonais (50 pontos por diagonal). Após a medição os valores foram somados para confecção de uma altura media da forragem por piquete e coletada a forragem a $5 \mathrm{~cm}$ do solo com um quadrado metálico de $1 \mathrm{~m}^{2}$ em um ponto do piquete que cuja altura fosse igual a media obtida pela medição. Após a coleta, as amostras de cada piquete foram pesadas e homogeneizadas, e à partir dessas retiraram-se duas alíquotas compostas: uma para avaliação da disponibilidade total de matéria seca (MS/ha) e outra para análise das disponibilidades por hectare de MS de: folha verde, folha seca, colmo verde e colmo seco. A avaliação da forragem ingerida pelos animais foi realizada utilizando a técnica da simulação manual de pastejo, coletando-se amostras de forragem em duas linhas diagonais dentro de cada piquete no primeiro dia de cada período experimental, procurando manter sempre os mesmos amostradores, com vistas à diminuição na variabilidade dos resultados.

Todo o material coletado foi imediatamente congelado em freezer a $-20^{\circ} \mathrm{C}$ para posterior análise de laboratório. Também foram feitas amostragens dos ingredientes usados para a formulação do suplemento e dos suplementos depois de misturados. As amostras dos ingredientes, suplementos e forragem foram analisados no laboratório de nutrição animal da Universidade Federal de Mato Grosso (UFMT) e da Universidade de Cuiabá (UNIC), para as seguintes variáveis: matéria seca (MS), proteína bruta (PB), extrato etéreo (EE), fibra em detergente neutro (FDN) e matéria mineral $(\mathrm{MM})$ realizadas de acordo com as técnicas descritas por Silva e Queiroz (2002).

As concentrações de fibra em detergente neutro indigestivel (FDNi) foram determinadas por intermédio da digestibilidade in situ, obtida após incubação por 144 horas, segundo o método descrito por Cochran et al. (1986). Das amostras destinadas à estimativa da disponibilidade total de MST de forragem, foi calculado o percentual de matéria seca potencialmente digestível (MSpd) ofertada aos animais. Esse resultado foi obtido por intermédio do resíduo insolúvel em detergente neutro (FDNi), segundo a equação: $\mathrm{MSpd}=0,98 \times(100-\mathrm{FDN})$ $+($ FDN - FDNi), Onde: 0,98 = coeficiente de digestibilidade verdadeiro do conteúdo celular e FDNi $=$ FDN indigestível.

Os carboidratos totais (CT) da forragem foram obtidos pela equação proposta por Sniffen et al. (1992): $\mathrm{CT}=100-(\% \mathrm{~PB}+\% \mathrm{EE}+\%$ Cinzas $)$. Os carboidratos totais (CT) dos suplementos foram obtidos pela equação proposta por Hall (2000): CNF $=100-[(\% \mathrm{~PB}-\%$ PBureia $+\%$ ureia $)+\% \mathrm{FDN}+$ $\% \mathrm{EE}+\% \mathrm{MM}]$. Os carboidratos não fibrosos $(\mathrm{CNF})$, pela diferença entre CT e FDN.

No $28^{\circ}$ dia de cada período experimental foram 
feitas avaliações do comportamento de pastejo diurno dos animais. Essas avaliações eram feitas com uso da observação visual das atividades praticadas pelos animais, sendo estas divididas em: Pastejo, cocho, água, ócio e ruminação. As avaliações foram realizadas a cada 10 minutos em um período correspondido entre as 06:00 horas da manhã e as 18:00 horas da tarde, totalizando sempre 12 horas de avaliação.

Para a avaliação econômica, o valor atribuído a tonelada de cada ingrediente foi obtido por cotação de preço no mercado local em três fornecedores diferentes. $\mathrm{O}$ custo dos suplementos foi calculado em função do nível de inclusão de cada ingrediente multiplicado pelo seu respectivo preço por unidade de produto $(\mathrm{kg})$. O custo por dia com suplemento (R\$) foi calculado multiplicando-se o consumo de suplemento animal/dia pelo preço por $\mathrm{kg}$ de suplemento. Para o custo com forragem foi considerado o valor de aluguel de pasto de $\mathrm{R} \$ 10,00$ animal/mês. O custo diário total foi obtido pela soma dos custos diários com mão de obra, forragem e suplemento. Para calcular o custo da mão de obra, assumiu-se a contratação de um funcionário com capacidade para cuidar de 500 animais sendo a sua remuneração mensal de $\mathrm{R} \$ 1.000,00$. Foi considerado como tempo gasto pelo funcionário com a suplementação dos animais de uma hora por dia, ou seja, R\$125,00 mês de custo com o fornecimento dos suplementos. Foram considerados os mesmos custos com mão-de-obra para os suplementos energético, múltiplo e protéico, pois estes suplementos foram fornecidos diariamente. Já para mistura mineral assumiu-se freqüência semanal de reabastecimento dos cochos. A margem bruta por $\mathrm{kg}$ de ganho foi calculada pela diferença entre o valor pago por $\mathrm{kg}$ de produto e o custo diário total para que o animal produzisse esse $\mathrm{kg}$ de ganho. Os dias para atingir $350 \mathrm{~kg}$ de peso corporal (PC) foram obtidos pela equação: D350=(350-PC final)/GMD. Os custos com forragem, mão de obra e suplemento para os animais atingiram $350 \mathrm{~kg}$ de PC foram obtidos multiplicando-se os custos diários com cada um dos itens pelos dias adicionais para atingir os $350 \mathrm{~kg}$ de $\mathrm{PC}$. A receita aos $350 \mathrm{~kg}$ de $\mathrm{PC}$ foi obtida pela equação: Receita $350 \mathrm{PC}=(350 * \mathrm{R} \$$ pago por $\mathrm{kg}$ ). Foi considerado como valor da arroba do boi de $\mathrm{R} \$ 70,20$, ou seja $\mathrm{R} \$ 2,34$ por $\mathrm{kg}$ de PC considerando $50 \%$ de rendimento de carcaça e $\mathrm{R} \$$ 650,00 para o bezerro de reposição. A margem bruta sem a reposição foi calculada subtraindo-se da receita o custo total para atingir $350 \mathrm{~kg}$ de PC. A margem bruta com a reposição foi calculada subtraindo-se da receita o custo total para atingir $350 \mathrm{~kg}$ de PC adicionado do custo com a reposição.

As análises referentes ao desempenho e comportamento de pastejo dos animais experimentais foram conduzidas considerando um delineamento inteiramente casualizado, segundo o modelo estatístico:

$\mathrm{y}_{\mathrm{ij}}=\mu+\mathrm{t}_{\mathrm{i}}+\mathrm{e}_{\mathrm{ij}}$ em que:

$\mu=$ constante geral; $t_{i}=$ efeito do suplemento $i$, sendo $\mathrm{i}=1,2,3$ e 4 ; $\mathrm{e}_{\mathrm{ij}}=$ erro aleatório, associado a cada observação, pressuposto NID $\left(0, \sigma^{2}\right)$.

Paralelamente ao experimento para determinação do desempenho e comportamento ingestivo, em área experimental anexa, foi conduzido experimento para determinação do $\mathrm{pH}$ e $\mathrm{N}_{-} \mathrm{NH}_{3}$ ruminal. Para este experimento foram usados 4 animais contemporâneos aos animais usados para determinação do desempenho e comportamento ingestivo, distribuídos em delineamento experimental quadrado latino $4 \times 4$, segundo modelo extatistico:

$y i j k=\mu+A i+\beta j+P k+e i j k$, em que:

$\mu=$ constante geral; $\alpha \mathrm{i}=$ efeito do suplemento $\mathrm{i}(\mathrm{i}=1,2,3$ e 4$) ; \beta \mathrm{j}=$ efeito referente ao animal ou sequência de tratamentos $\mathrm{j}(\mathrm{j}=1,2,3$ e 4); $\mathrm{Pk}$ $=$ efeito referente ao período experimental $\mathrm{k}(\mathrm{k}=$ 1, 2, 3 e 4); e eij = erro aleatório, associado a cada observação, pressuposto $\operatorname{NID}\left(0, \sigma^{2}\right)$.

Cada período experimental correspondeu a 14 dias. Do primeiro ao $13^{\circ}$ dia experimental, os animais apenas foram adaptados aos suplementos. 
A coleta de líquido ruminal para a determinação do $\mathrm{pH}$ e do nitrogênio amoniacal $\left(\mathrm{N}-\mathrm{NH}_{3}\right)$ foi realizada no $14^{\circ}$ dia do período experimental. O líquido ruminal foi coletado nos tempos zero hora (antes do fornecimento do suplemento) e 4 horas (4 horas após o fornecimento do suplemento), com auxilio de uma sonda esofágica e filtrado em um béquer com auxilio de duas peneiras de porosidade $2 \mathrm{~mm}$ sobrepostas uma a outra. A leitura do $\mathrm{pH}$ foi realizada com um peagâmetro digital imediatamente após a coleta do material. Após a leitura do $\mathrm{pH}$, uma alíquota de 50 $\mathrm{mL}$ foi acondicionada em recipiente de plástico com $1 \mathrm{~mL}$ de ácido sulfúrico $\left(\mathrm{H}_{2} \mathrm{SO}_{4}\right)$ 1:1 e congelada a $-20^{\circ} \mathrm{C}$, para posteriores análises das quantidades de nitrogênio amoniacal ruminal $\left(\mathrm{N}-\mathrm{NH}_{3}\right)$.

Os dados foram analisados por meio de analise de variância e para comparações entre médias, adotouse o teste de Student Newman Keulls, sendo todas as análises realizadas por intermédio do programa Saeg - UFV (2001), adotando nível de significância de $5 \%$.

\section{Resultados e Discussão}

Foram observados valores médios de massa de forragem total (MSFT), de matéria seca potencialmente digestível (MSpD), de lâminas foliares verdes (MSLV), de lâminas foliares mortas (MSLM), de colmos verdes (MSCV) e de colmos mortos (MSCM) na pastagem de 3.950; 2.300; $1.050 ; 680 ; 1.180$ e $1.040 \mathrm{~kg} \mathrm{ha}^{-1}$, respectivamente (Figura 1). O comportamento dos dados de disponibilidade encontrado está de acordo com os observados por Paula et al. (2011), em pastagem de Brachiaria brizantha cv. Marandu com aumento MSCV e diminuição da MSLV em função dos períodos de pastejo.

Figura 1. Massa seca de forragem total (MSFT), de matéria seca potencialmente digestível (MSpD), de lamina foliares verdes (MSLV), de laminas foliares mortas (MSLM), de colmos verdes (MSCV) e de colmos mortos (MSCM) do capim Marandu em cada período experimental.

MSFT $\square$ MSpD $\square$ MSLV $\square$ MSLM $\square$ MSCV $\square$ MSCM

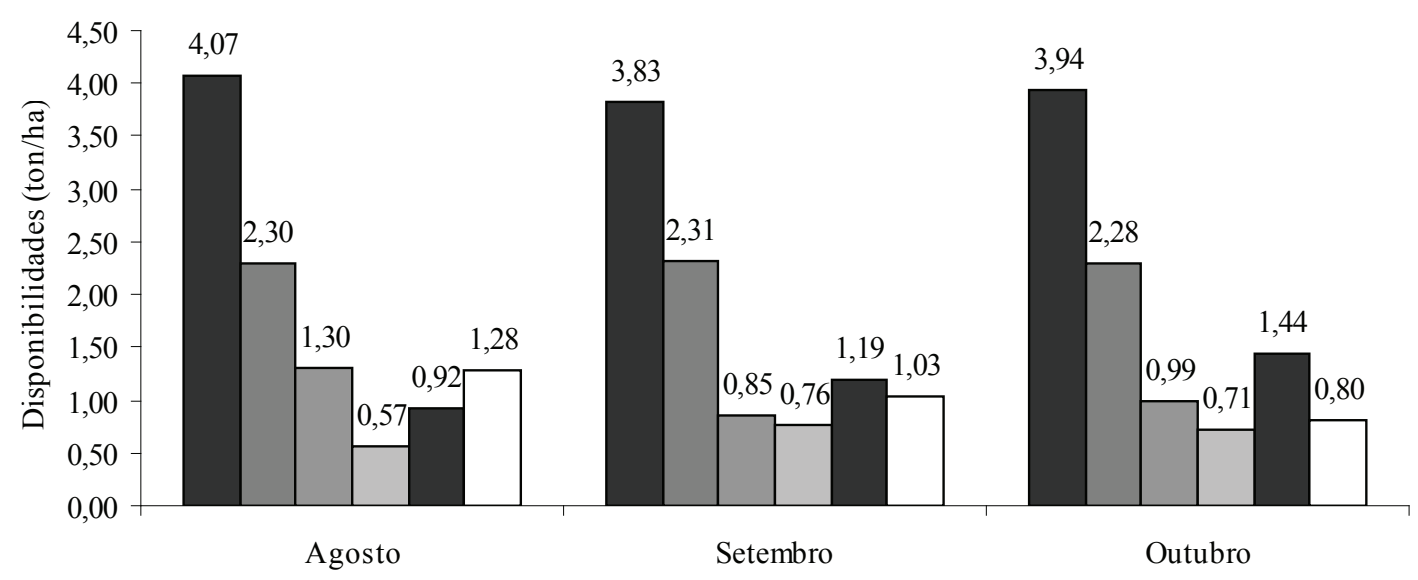

Fonte: Elaboração dos autores.

Foram observados valores médios para ofertas de massa de forragem total (OMSFT), de matéria seca potencialmente digestível (OMSpD), de lâminas foliares verdes (OMSLV), de lâminas foliares mortas
(OMSLM), de colmos verdes (OMSCV) e de colmos mortos (OMSCM) na pastagem de 21,$01 ; 12,21$; 5,$63 ; 3,58 ; 6,17$ e $5,63 \%$ do $\mathrm{PC}$, respectivamente (Figura 2). Considerando o consumo de matéria 
seca de 2,30\% do PC para novilhos com PC médio de $300 \mathrm{~kg}$ animal ${ }^{-1}$, obtidos por Nascimento et al. (2010) em pastagens de Brachiaria decumbens Stapf, o valor médio para OMSFT observado nesse experimento é 9,13 vezes a capacidade de consumo dos animais. Entretanto, apesar de a OMSFT ser adequada, a OMSLV de 5,63\% do PC encontra-se abaixo dos valores encontrados por Machado et al. (2008) que trabalhando com ofertas de forragem variando entre 4 e $16 \%$ do $\mathrm{PC}$, obteve máximo desempenho animal com OMSLV entre 10 e $12 \%$ do PC.

Figura 2. Ofertas diárias de Massa seca de forragem total (OMSFT), de matéria seca potencialmente digestível (OMSpD), de lamina foliares verdes (OMSLV), de laminas foliares mortas (OMSLM), de colmos verdes (OMSCV) e de colmos mortos (OMSCM) do capim Marandu em cada período experimental em porcentagem do peso corporal dos animais.

$\square$ OMSFT $\square$ OMSpD $\square$ OMSLV $\square$ OMSLM $\square$ OMSCV $\square$ OMSCM

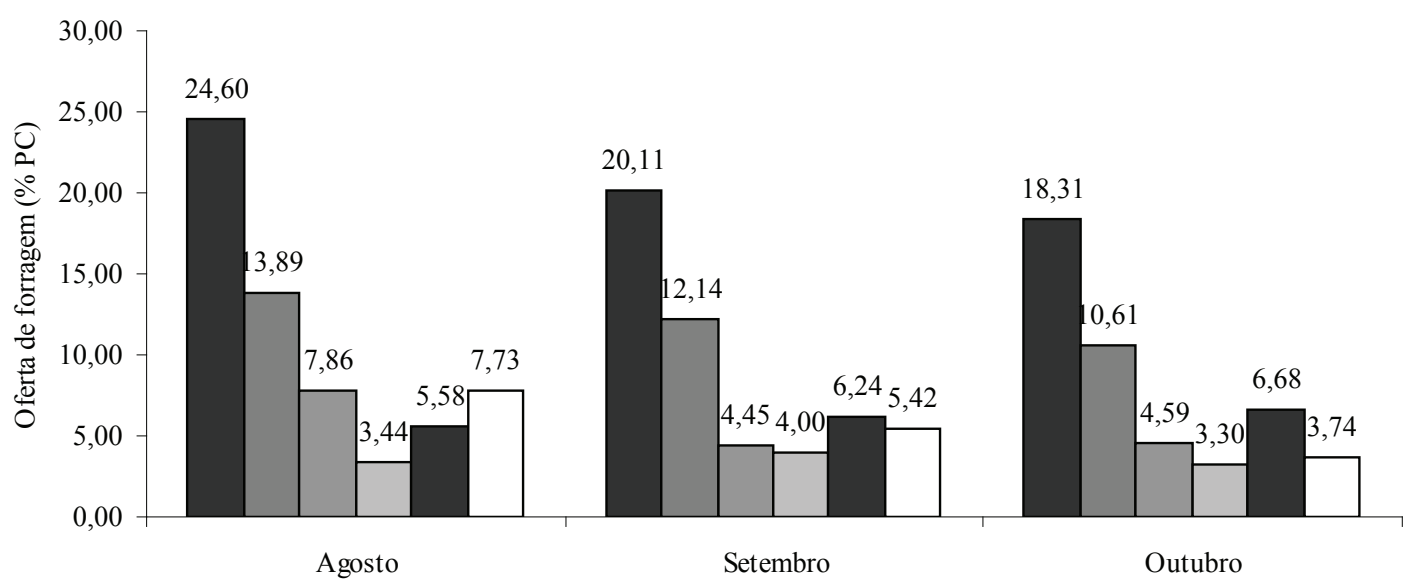

Fonte: Elaboração dos autores.

Para Paulino, Detmann e Valadares Filho (2008) a interpretação da oferta de forragem disponível ao pastejo animal deve ser feita sob a ótica da fração potencialmente convertível em produto animal, alcançado pela utilização da OMSpD. Segundo Paulino et al. (2006) a OMSpD que potencializa o desempenho animal é de 5 a $6 \%$ do PC animal $\mathrm{dia}^{-1}$, sendo o valor médio encontrado para este experimento de $12,21 \%$, não sendo limitante ao desempenho animal. A forragem disponível ao pastejo animal possuía em média 6,58\% de $\mathrm{PB}$ (Tabela 3), abaixo de 7,0 e 10,0\% de PB citados por Minson (1990) e Detmann, Paulino e Valadares Filho (2010) como limitantes à utilização dos carboidratos fibrosos da forragem pastejada. 
Tabela 3. Teores médios de matéria seca (MS\%), Proteína bruta (PB), fibra em detergente neutro (FDN), extrato etéreo (EE), fibra em detergente neutro indigestivel (FDNi), carboidratos totais (CT), carboidratos não fibrosos (CNF) e cinzas (CZ) em amostras obtida via simulação de pastejo em cada período experimental para Brachiaria brizanta cv. Marandú.

\begin{tabular}{lcccc}
\hline \multirow{2}{*}{ Itens } & \multicolumn{3}{c}{ Meses experimentais } & \multirow{2}{*}{ Média } \\
\cline { 2 - 4 } & Agosto & Setembro & Outubro & 39,51 \\
MS (\%) & 32,53 & 39,12 & 46,87 & 6,58 \\
$\mathrm{~PB}^{1}$ & 7,44 & 6,49 & 5,82 & 1,06 \\
$\mathrm{EE}^{1}$ & 1,02 & 1,07 & 1,09 & 71,96 \\
$\mathrm{FDN}^{1}$ & 67,55 & 71,27 & 77,06 & 32,85 \\
$\mathrm{FDNi}^{1}$ & 30,42 & 33,49 & 34,65 & 82,90 \\
$\mathrm{CT}^{1}$ & 82,3 & 82,6 & 83,81 & 10,94 \\
$\mathrm{CNF}^{1}$ & 14,75 & 11,33 & 6,75 & 9,45 \\
$\mathrm{CZ}^{1}$ & 9,24 & 9,84 & 9,28 & 46,34 \\
NDTest $^{2}$ & 49,66 & 46,75 & 42,59 & \\
\hline
\end{tabular}

${ }^{1}$ Expresso em \% da matéria seca; ${ }^{1} \mathrm{NDT}=91,6086-0,669233(\mathrm{FDN})+0,437932(\mathrm{~PB})$ (CAPELLE et al., 2001).

Fonte: Elaboração dos autores.

Observa-se que os suplementos SE, SM e SP possuem 8,$13 ; 22,87$ e $56,62 \%$ de $\mathrm{PB}$, respectivamente (Tabela 4). O aumento do teor proteico dos suplementos está diretamente relacionado com a inclusão de farelo de soja, ureia e sulfato de amônia nas formulações.

Tabela 4. Teores médios de matéria seca (MS\%), Proteína bruta (PB), fibra em detergente neutro (FDN), extrato etéreo (EE), fibra em detergente neutro indigestivel (FDNi), carboidratos totais (CT), carboidratos não fibrosos (CNF) e cinzas (CZ) nos suplementos e ingredientes usados no experimento.

\begin{tabular}{lccccc}
\hline \multirow{2}{*}{ Itens } & \multicolumn{5}{c}{ Suplementos experimentais e ingredientes } \\
\cline { 2 - 5 } & $\mathrm{SE}$ & $\mathrm{SM}$ & $\mathrm{SP}$ & Milho grão & Farelo de Soja \\
\hline MS (\%) & 88,97 & 88,23 & 87,99 & 87,89 & 90,77 \\
$\mathrm{~PB}^{1}$ & 8,13 & 22,87 & 56,62 & 9,63 & 41,34 \\
$\mathrm{EE}^{1}$ & 3,02 & 3,19 & 4,01 & 3,29 & 4,32 \\
$\mathrm{FDN}^{1}$ & 19,09 & 24,67 & 21,60 & 21,37 & 23,74 \\
$\mathrm{FDNi}^{1}$ & 10,84 & 9,55 & 9,51 & 9,17 & 9,03 \\
$\mathrm{CT}^{1}$ & 82,83 & 68,62 & 30,06 & 86,22 & 48,29 \\
$\mathrm{CNF}^{1}$ & 63,74 & 52,25 & 3,46 & 64,85 & 24,55 \\
$\mathrm{CZ}^{1}$ & 6,02 & 5,32 & 9,31 & 0,86 & 6,05 \\
NDTest $^{2}$ & 83,60 & 78,40 & 72,00 & 88,00 & 80,00 \\
\hline
\end{tabular}

${ }^{1}$ Expresso em \% da matéria seca; ${ }^{2}$ Tabelas brasileiras de composição de alimentos para bovinos (VALADARES FILHO; PAULINO; MAGALHÃES, 2006).

Fonte: Elaboração dos autores.

Os teores de FDN de 19,09; 24,67 e 21,60 para SE, SM e SP estão relacionados à baixa quantidade de FDN dos ingredientes (milho e farelo de soja) usados na formulação dos suplementos. Não houve diferença significativa $(\mathrm{P}<0,05)$ para as atividades comportamentais dos 
animais (Figura 3). Os animais recebendo apenas 1,20 horas maior que a média (7,00 horas) dos a mistura mineral tiveram tempo de pastejo de animais suplementados.

Figura 3. Tempos despedidos para as atividades de Ócio, consumo de suplemento, ruminação, consumo de água e pastejo.

$\mathrm{MM} \square \mathrm{SE} \square \mathrm{SM} \square \mathrm{SP}$

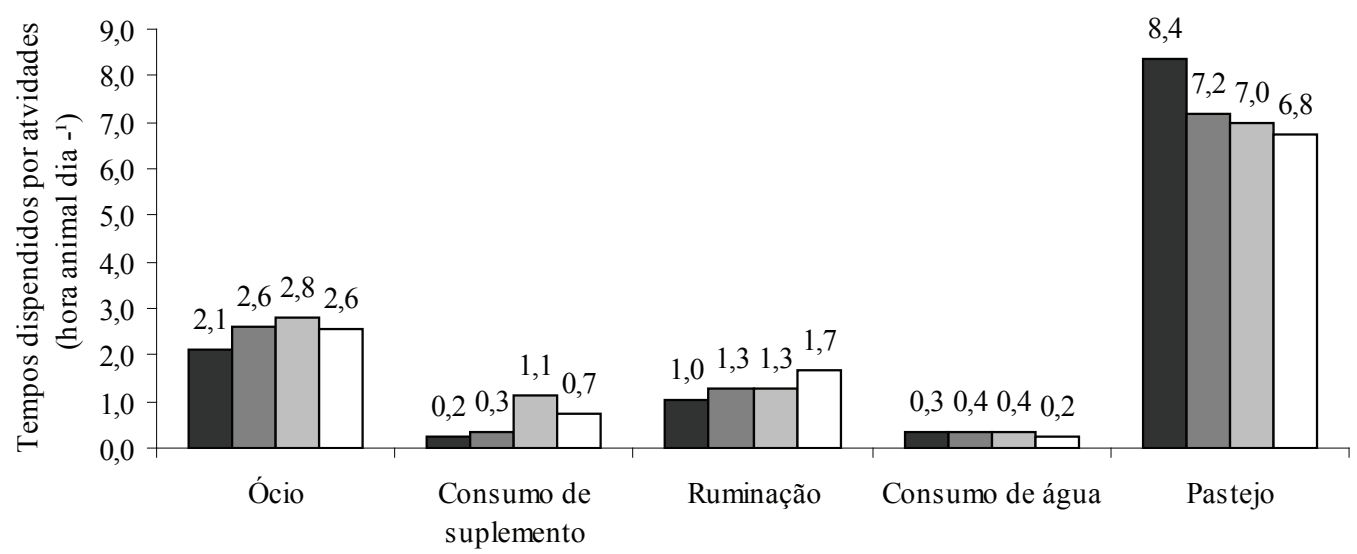

Fonte: Elaboração dos autores.

Silva et al. (2010), suplementaram novilhos em pastagens de capim Marandu de média qualidade recebendo suplementação mineral, energética e protéica em níveis de zero (mistura mineral), 0,3; 0,6 e $0,9 \%$ do $\mathrm{PC}$, verificaram efeito quadrático da suplementação, com diminuição no tempo de pastejo e ócio a partir de $0,5 \%$ do PC de suplemento fornecido e aumento linear no tempo de cocho com o aumento do nível de suplementação.

Não houve diferença estatística $(\mathrm{P}>0,05)$ entre os suplementos para a concentração de $\mathrm{N}-\mathrm{NH}_{3}$ ruminal no tempo quatro horas. Os valores de pH não são limitantes ao crescimento microbiano (Tabela 5).

Os suplementos múltiplo (SM) e proteico (SP) forneceram quantidades de $\mathrm{N}_{-} \mathrm{NH}_{3}$ ruminal suficientes para potencializar a digestão da fibra da forragem, que segundo Detmann, Paulino e Valadares Filho (2010) é de 13,0 $\mathrm{mg} \mathrm{dL}^{-1}$ de líquido ruminal.

Tabela 5. Consumo de suplemento (CS), médias e coeficientes de variação (CV) para os valores de pH e concentrações de nitrogênio amoniacal ruminal $\left(\mathrm{N}^{-\mathrm{NH}_{3}}\right)\left(\mathrm{mg} \mathrm{dL}^{-1}\right)$, em função dos diferentes suplementos.

\begin{tabular}{|c|c|c|c|c|c|c|c|}
\hline \multirow{2}{*}{ Variáveis } & \multirow{2}{*}{$\begin{array}{l}\text { Tempo } \\
\text { (horas) }\end{array}$} & \multicolumn{4}{|c|}{ Tratamentos } & \multirow{2}{*}{$\mathrm{P}$} & \multirow{2}{*}{ CV (\%) } \\
\hline & & $\mathrm{MM}$ & SE & SM & SP & & \\
\hline $\mathrm{N}-\mathrm{NH}_{3}$ & zero & $7,44 b$ & $6,82 b$ & $7,96 \mathrm{~b}$ & $13,39^{\mathrm{a}}$ & 0.03441 & 33,37 \\
\hline $\mathrm{N}-\mathrm{NH}_{3}$ & quatro & $9,76 a$ & $9,54^{\mathrm{a}}$ & $14,96 a$ & $15,84^{\mathrm{a}}$ & NS & 43,46 \\
\hline $\mathrm{pH}$ & zero & $6,93 a$ & $6,62^{\mathrm{a}}$ & $6,96 a$ & $6,94^{\mathrm{a}}$ & NS & 5,08 \\
\hline $\mathrm{pH}$ & quatro & $6,77 \mathrm{a}$ & $6,74^{\mathrm{a}}$ & $6,63 a$ & $6,73^{\mathrm{a}}$ & NS & 2,03 \\
\hline CS (kg/dia) & & 0,067 & 1,0 & 1,0 & 1,0 & & \\
\hline
\end{tabular}

Valores seguidos de letras iguais na linha, não diferem pelo teste SNK a 5\% de significância.

Fonte: Elaboração dos autores. 
Houve diferença para o GMD entre os animais suplementados $(\mathrm{P}<0,05)$ e aqueles que receberam apenas mistura mineral, porém, não foi observada diferença entre os suplementos $\mathrm{SE}, \mathrm{SM}$ e $\mathrm{SP}(\mathrm{P}>0,05)$. Os suplementos SM e SP possibilitaram ganho de peso adicional em relação à mistura mineral de 0,350 e $0,320 \mathrm{~kg}$ animal $\mathrm{dia}^{-1}$ respectivamente (Tabela 6). $\mathrm{O}$ maior desempenho para os animais recebendo os suplementos múltiplo (SM) e proteico $(\mathrm{SP})$ pode ser resultado da interação positiva entre quantidade de $\mathrm{N}^{-\mathrm{NH}_{3}}$ ruminal, degradação da fibra da forragem e aumento da taxa de passagem da FDNi.

Tabela 6. Valores médios de peso corporal inicial (PC Inicial) e final (PC Final), ganhos de peso total (GP Total), ganho médio diário (GMD) e consumo de suplemento para os diferentes suplementos experimentais.

\begin{tabular}{lccccc}
\hline \multirow{2}{*}{ Item } & \multicolumn{3}{c}{ Suplementos } & \multirow{2}{*}{ CV (\%) } \\
\cline { 2 - 5 } & MM & SE & SM & SP & \\
\hline PC Inicial $(\mathrm{kg})$ & 171,40 & 171,20 & 172,40 & 171,00 & - \\
PC Final (kg) & 203,20 & 221,40 & 235,40 & 232,20 & 4,30 \\
GP Total (kg) & 31,80 & 50,20 & 63,00 & 61,20 & 18,87 \\
GMD (kg) & $0,380^{\mathrm{b}}$ & $0,600^{\mathrm{a}}$ & $0,750^{\mathrm{a}}$ & $0,730^{\mathrm{a}}$ & 18,87 \\
Ganho diferencial à mistura mineral (kg) & - & 0,220 & 0,370 & 0,350 & - \\
Consumo de suplemento (kg/dia) & 0,067 & 1,00 & 1,00 & 1,00 & - \\
\hline
\end{tabular}

Valores seguidos de letras iguais na linha, não diferem pelo teste SNK a 5\% de significância.

Fonte: Elaboração dos autores.

Outro fator a se considerar no maior desempenho dos animais recebendo suplementos múltiplo (MS) e proteico (SP), ou mesmo do suplemento energético (SE), é expressão do efeito aditivo substitutivo, onde o animal deprime o consumo de forragem, porém aumenta o consumo de matéria seca total. Quando esse efeito ocorre, há incremento no consumo de energia e proteína pelo animal em função da maior concentração desses componentes no suplemento, melhorando a digestibilidade da dieta total, proporcionando maior aporte de nutrientes e aumento do desempenho animal.

Segundo Acedo (2004), esses ganhos também são de grande importância na suplementação estratégica, visto que, boa parte do lucro obtido na pecuária de corte nacional é fruto da oportunidade de venda do boi gordo em épocas de maior preço da arroba, e não somente da eficiência no processo produtivo. Esse mesmo autor, avaliando diferentes fontes de proteína sobre o desempenho de animais em recria durante o período das águas, não encontrou diferença significativa, embora numericamente, tenham sido obtidos ganhos médios diários de até 180 g em relação ao controle, quando utilizado suplemento múltiplo à base de farelo de soja e farelo de glúten de milho.

Os resultados deste trabalho confirmam a afirmativa de Paulino, Detmann e Valadares Filho (2008) de que animais freqüentemente respondem à suplementação proteica em pastagens de boa qualidade, com ganhos adicionais de 200 a $300 \mathrm{~g}$. Isso pode não ser significativo quando se compara apenas o ganho de peso com o custo do suplemento múltiplo, principalmente em épocas em que o custo do suplemento é alto, mas pode causar grande impacto no sistema de produção como um todo.

A desocupação de áreas para o diferimento das pastagens e o uso destas por categorias de animais mais jovens e eficientes em converter alimento em produto animal possivelmente seria uma das maiores vantagens da suplementação em um sistema pecuário de precisão e/ou ciclo curto. Villela et al. (2009) ressaltou que os ganhos adicionais obtidos 
nesta fase podem viabilizar o abate desses animais antes da segunda seca, ou seja, em torno de 20 meses de idade, o que, além de levar a um giro mais rápido do capital, facilita o manejo na fazenda. Ressalta-se que a intensidade da resposta de um suplemento proteico depende da qualidade e da disponibilidade do pasto. Os suplementos proteicos podem promover aumento do consumo de forragem por fornecerem $\mathrm{N}-\mathrm{NH}_{3}$ para os microrganismos ruminais.

Os custos mais elevados por $\mathrm{kg}$ de suplemento para SM e SP são reflexo da inclusão de farelo de soja como principal ingrediente proteico dos suplementos. Este fato foi marcante para o SP, que notadamente teve o seu custo unitário aumentado em R \$ 0,36 sendo 28\% superior ao SM (Tabela 7). Observa-se que na medida que o farelo de soja é incluso no suplemento, o custo desse último aumenta em função dos maiores custos do farelo de soja em comparação ao milho (Tabelas 7 e 2), com reflexo direto sobre o custo diário total, o qual aumenta à medida que a quantidade de PB do suplemento se eleva.

Mesmo com ganho de peso inferior $(0,130 \mathrm{~kg}$ animal $\mathrm{dia}^{-1}$ ) ao proporcionado pelo suplemento proteico, o suplemento energético produziu margem bruta superior àquela produzida pelos suplementos SP e SM (R $\$ 0,47$ e $\mathrm{R} \$ 0,11$, respectivamente), porém com margem bruta inferior à verificada com a mistura mineral ( $\mathrm{R} \$ 0,30)$. Entretanto, o GMD observado para os animais submetidos à mistura mineral foi inferior ao verificado para os suplementos energético, múltiplo e proteico $(0,220$; 0,370 e 0,350 kg animal $\mathrm{dia}^{-1}$, respectivamente).

Com base nessa análise preliminar, os melhores desempenhos econômicos correspondem de maneira decrescente à mistura mineral, SE, SM e $\mathrm{SP}$, respectivamente, contrariando o pressuposto teórico de que a utilização de suplementos múltiplos ou proteicos, para animais mantidos em pastagens de média qualidade melhoraria o desempenho produtivo e econômico dos sistemas de produção.

Tabela 7. Indicadores econômicos obtidos em função dos suplementos.

\begin{tabular}{|c|c|c|c|c|}
\hline \multirow{2}{*}{ Indicadores Econômicos } & \multicolumn{4}{|c|}{ Suplementos } \\
\hline & MM & SE & SM & SP \\
\hline Custo Suplemento (R $\$ /$ ton $)^{1}$ & 1150,00 & 390,00 & 502,50 & 860,00 \\
\hline Custo suplemento $(\mathrm{R} \$ / \mathrm{kg})^{1}$ & 1,15 & 0,39 & 0,50 & 0,86 \\
\hline GMD (kg/dia) & 0,38 & 0,6 & 0,75 & 0,72 \\
\hline Consumo suplemento (kg/dia) & 0,067 & 1,000 & 1,000 & 1,000 \\
\hline Custo por dia com suplemento (R\$) & 0,08 & 0,39 & 0,50 & 0,86 \\
\hline Custo por dia com mão de obra (R\$) & 0,002 & 0,008 & 0,008 & 0,008 \\
\hline Custo por dia com forragem $(\mathrm{R} \$ / \text { dia })^{2}$ & 0,33 & 0,33 & 0,33 & 0,33 \\
\hline Custo diário total $(\mathrm{R} \$ / \mathrm{dia})^{3}$ & 0,41 & 0,73 & 0,84 & 1,20 \\
\hline Margem bruta por kg de ganho ${ }^{4}$ & 1,93 & 1,61 & 1,50 & 1,14 \\
\hline
\end{tabular}

${ }^{1}$ Valores sazonais sujeitos as flutuações de mercado; ${ }^{2}$ Valor de aluguel de pastagens de R\$ 10,00 animal/mês; ${ }^{3}$ Soma dos custos com forragem, mão de obra e suplementos; ${ }^{4}$ Margem bruta=Receita-custo.

Fonte: Elaboração dos autores.

Cabral et al. (2008) suplementando novilhos em pastagens de Panicum maximum cv. Tanzânia com mistura mineral e níveis de suplementação de 0,2 ; 0,4 e $0,6 \%$ do PC com $22 \%$ de PB encontraram aumento e diminuição lineares da receita e margem bruta, respectivamente, com o aumento do nível de suplementação, sendo estes resultados semelhantes aos encontrados no presente estudo, com o aumento 
do nível de proteína bruta entre os suplementos utilizados. O autor supracitado não considerou a desocupação das pastagens e o ganho adicional com a suplementação em relação a mistura mineral no ciclo de produção indicando o uso da mistura mineral na condição de seu trabalho, porem ressalta que a suplementação proporcionou $0,180 \mathrm{~kg}$ animal $\mathrm{dia}^{-1}$ de ganho adicional e que este adiantaria em 20 dias a terminação dos animais com benefícios sobre ocupação da terra, gasto com energia de mantença dos animais, mão de obra, vacinas e medicamentos.

Adicionalmente a esta primeira análise econômica na tentativa de considerar a tecnologia da suplementação na perspectiva de um sistema de produção de novilho precoce a pasto, com o final do período de recria quando os animais atingem $350 \mathrm{~kg}$ de PC, procedeu-se uma segunda análise econômica, considerando a vantagem da desocupação das pastagens, mão-de-obra e do ganho adicional da suplementação (Tabela 8).

Os animais que receberam apenas a mistura mineral necessitam de 172, 234 e 223 dias a mais que os animais recebendo SE, SM e SP para atingir $350 \mathrm{~kg}$ de $\mathrm{PC}$, o que produz um custo adicional com pastagens em relação aos animais recebendo suplementos SE, SM e SP de R\$ 56,81; 77,06 e 73,58 .

Quando são comparadas as margens brutas com a reposição de animais para os suplementos usados, observam-se valores positivos para a mistura mineral ( $\mathrm{R} \$ 10,76)$, suplemento energético ( $\mathrm{R} \$$ $12,48)$ e suplemento SM ( $\mathrm{R} \$ 40,12)$, enquanto que para o suplemento SP a margem bruta encontrada foi negativa ( $\mathrm{R} \$-27,34)$.

Nesse contexto, o uso de suplementos Múltiplos (SM) para animais em pastejo aumentou o desempenho econômico da atividade de recria em $\mathrm{R} \$ 29,36$ por animal ciclo em relação à mistura mineral, R\$ 27,64 em relação a SE e R\$ 67,46 em relação à SP. Assim a redução na duração do tempo de recria em 234 dias permite ao pecuarista a condução de mais um ciclo produtivo na mesma área dobrando a capacidade da propriedade rural de recriar animais e produzir receita.

Tabela 8. Indicadores econômicos obtidos considerando recria dos animais até $350 \mathrm{~kg}$ de peso corporal (PC).

\begin{tabular}{|c|c|c|c|c|}
\hline \multirow{2}{*}{ Indicadores no ciclo de Produção } & \multicolumn{4}{|c|}{ Suplementos } \\
\hline & MM & SE & SM & SP \\
\hline Dias para $350 \mathrm{~kg}$ de $\mathrm{PC}(\mathrm{D} 350)^{1}$ & 386,84 & 215,00 & 153,33 & 163,89 \\
\hline Ganho de peso adicional para atingir $350 \mathrm{~kg}$ de $\mathrm{PC}$ & 147,00 & 129,00 & 115,00 & 118,00 \\
\hline Custo forragem para atingir $350 \mathrm{~kg}$ de $\mathrm{PC}^{3}$ & 127,66 & 70,95 & 50,60 & 54,08 \\
\hline Custo mão de obra para atingir $350 \mathrm{~kg}$ de PC & 0,77 & 1,72 & 1,23 & 1,31 \\
\hline Custo suplemento para atingir $350 \mathrm{~kg}$ de $\mathrm{PC}^{2}$ & 29,81 & 83,85 & 77,05 & 140,94 \\
\hline Custo total para atingir $350 \mathrm{~kg}$ de $\mathrm{PC}^{4}$ & 158,24 & 156,52 & 128,88 & 196,34 \\
\hline Receita aos $350 \mathrm{~kg}$ de $\mathrm{PC}^{7}$ & 819,00 & 819,00 & 819,00 & 819,00 \\
\hline Margem bruta no ciclo de produção sem a reposição ${ }^{5}$ & 660,76 & 662,48 & 690,12 & 622,66 \\
\hline Valor pago pelo bezerro de reposição (R $\$$ /cabeça) & 650,00 & 650,00 & 650,00 & 650,00 \\
\hline Margem bruta no ciclo de produção com a reposição ${ }^{6}$ & 10,76 & 12,48 & 40,12 & $-27,34$ \\
\hline
\end{tabular}

${ }^{1} \mathrm{D} 350=(350-\mathrm{PC}$ final $) / \mathrm{GMD} ;{ }^{2}$ Valores sazonais sujeitos as flutuações de mercado; ${ }^{3}$ Valor de aluguel de pastagens de R $\$ 10,00$ animal/ mês; ${ }^{4}$ Soma dos custos com forragem, mão de obra e suplementos; ${ }^{5}$ Margem bruta=Receita-custo total; ${ }^{6} \mathrm{Margem}$ bruta $=(\mathrm{Receita}-$ (custo total+reposição)); ${ }^{7}$ Valor considerado para @ do boi com 50\% de rendimento de carcaça de R $\$ 70,20$.

Fonte: Elaboração dos autores. 
Porto et al. (2009) trabalhando com suplementos múltiplos com média de $35 \%$ de PB para animais em recria no período das águas em pastagens de capim Marandu encontrou retorno econômico de $\mathrm{R} \$ 37,74 ; \mathrm{R} \$ 35,62 ; \mathrm{R} \$ 35,44$ e $\mathrm{R} \$ 21,78$ por animal/ciclo para suplementos compostos por farelo de soja e farelo de algodão, farelo de soja, grão de soja triturado e grão de soja inteiro respectivamente, valores estes bem próximos ao entrado nesse estudo para o suplemento SM de R\$ 40,12. Para Porto et al. (2009) o uso de suplementos em pastagens de média a alta qualidade depende do valor e da disponibilidade das fontes proteicas no mercado e dos objetivos e metas em cada propriedade. Diante dessa afirmação, os resultados econômicos negativos obtidos pelo suplemento SP para este trabalho não inviabilizam a prática da suplementação proteica em pastagens de média a alta qualidade, todavia ressaltam a necessidade de adequação das fontes de proteínas usadas, do nível de fornecimento dos suplementos, bem como seus níveis protéicos e custos por unidade de produto produzido.

\section{Conclusões}

A utilização de suplemento múltiplo para novilhos em pastagens de capim Marandu de média qualidade, na época de transição secaáguas, em condição de alta oferta de matéria seca potencialmente digestível aumenta o desempenho animal em 49,33\% em relação à mistura mineral, aumenta a margem bruta em relação à mistura mineral e ao suplemento proteico quando considerado o peso de $350 \mathrm{~kg}$ para o final da recria. Enquanto que, a utilização de suplemento energético para novilhos produz margem bruta negativa em relação à mistura mineral, suplemento múltiplo e/ou suplemento proteico e nas mesmas condições de criação.

\section{Referencias}

ACEDO, T. S. Suplementos múltiplos para bovinos em terminação, durante a época seca, e em recria, nos períodos de transição seca-águas e águas. 2004.
Dissertação (Mestrado em Zootecnia) - Universidade Federal de Viçosa, Viçosa, MG.

CABRAL, L. S.; ZERVOUDAKIS, J. T.; COPPEDÊ, C. M.; SOUZA, A. L.; CARAMORI JÚNIOR, J. G.; POLIZEL NETO, A.; OLIVEIRA, I. S. Suplementação de bovinos de corte mantidos em pastagem de Panicum maximum cv. Tanzânia no período das águas. Revista Brasileira de Saúde e Produção Animal, Salvador, v. 9, n. 2, p. 293-302, abr.jun. 2008.

CAPELLE, E. R.; VALADARES FILHO, S. C.; SILVA, J. F. C.; CECON, P. R. Estimativas do valor energético a partir de características químicas e bromatológicas dos alimentos. Revista Brasileira de Zootecnia, Viçosa, MG, v. 30, n. 6, p. 1837-1856, 2001.

CARVALHO, D. M. G.; ZERVOUDAKIS, J. T.; CABAL, L. S.; PAULA, N. F.; MORAES, E. H. B. K.; OLIVEIRA, A. A.; KOSCHECK, J. F. W. Fontes de energia em suplementos múltiplos para recria de bovinos em pastejo no período da seca: desempenho e analise econômica. Revista Brasileira de Saúde e Produção Animal, Salvador, v. 10, n. 3, p. 760-773 jul./set. 2009.

COCHRAN, R. C.; ADAMS, D. C.; WALLACE, J. D.; GALYEAN, M. L. Predicting digestibility of different diets with internal markers: Evaluation of four potential markers. Journal of Animal Science, Champaign, v. 63, n. 5, p. 1476-1483, 1986.

COSTA,V. A. C.; DETMANN, E.; VALADARES FILHO, S. C.; PAULINO, M. F.; HENRIQUES, L. T.; MANTOVANI, H. C. Degradação in vitro da fibra em detergente neutro de forragem tropical de baixa qualidade em função de suplementação com proteína e/ ou carboidratos. Revista Brasileira de Zootecnia, Viçosa, MG, v. 37, n. 3, p. 494-503, 2008.

COUTINHO FILHO, J. L. V.; JUSTO, C. L.; PERES, R. M. Desenvolvimento ponderal de bezerras desmamadas em pastejo de Brachiaria decumbens com suplementação protéica e energética. Pesquisa Agropecuária Brasileira, Brasília, v. 40, n. 8, p. 817-823, ago. 2005.

DETMANN, E.; PAULINO, M. F.; VALADARES FILHO, S. C. Otimização do uso de recursos forrageiros basais. In: SIMPÓSIO DE PRODUÇÃO DE GADO DE CORTE - SIMCORTE, 7., 2010, Viçosa, MG. Anais... Viçosa, MG: UFV, 2010. p. 123-144.

EUCLIDES, V. P. B.; EUCLIDES FILHO, K.; ARRUDA, Z. J.; FIGUEIREDO, G. R. Desempenho de Novilhos em pastagens de Brachiaria decumbens submetidos a diferentes regimes alimentares. Revista Brasileira de Zootecnia, Viçosa, MG, v. 27, n. 2, p. 246-254, 1998.

EUCLIDES, V. P. B.; EUCLIDES FILHO, K.; COSTA, F. P.; FIGUEIREDO, G. R. Desempenho de novilhos F1s 
Angus-Nelore em pastagens de Brachiaria decumbens Submetidos a diferentes regimes alimentares. Revista Brasileira de Zootecnia, Viçosa, MG, v. 30, n. 2, p. 470481, 2001.

FIGUEIREDO, D. M.; OLIVEIRA, A. S.; SALES, M. F. L.; PAULINO, M. F.; VALE, S. M. L. R. Analise econômica de quatro estratégias de suplementação para recria e engorda de bovinos em sistema pasto suplemento. Revista Brasileira de Zootecnia, Viçosa, MG, v. 36, n. 5, p. 1443-1453, 2007.

HALL, M.B. Calculation of non-structural carbohydrate content of feeds that contain non-protein nitrogen. Gainesville: University of Florida, 2000. p. A-25. (Bulletin, 339).

MACHADO, L. A. Z.; FABRÍCIO, A. C.; GOMES, A.; ASSIS, P. G. G.; LEMPP, B.; MARASCHIN, G. E. Desempenho de animais alimentados com lâminas foliares, em pastagem de capim-marandu. Pesquisa Agropecuária Brasileira, Brasília, v. 43, n. 11, p. 16091616, nov. 2008.

MINSON, D. J. Forage in ruminant nutrition. Queensland: Academic Press, 1990. 483 p.

NASCIMENTO, M. L.; PAULINO, M. F.; DETMANN, E.; LEÃO, M. I.; VALADARES FILHO, S. C.; HENRIQUES, L. T. Fontes de energia em suplementos múltiplos para novilhos em pastejo durante o período das águas. Revista Brasileira de Zootecnia, Viçosa, MG, v. 39, n. 4, p. 861-872, 2010.

PAULA, N. F.; ZERVOUDAKIS, J. T.; CABRAL, L. S.; CARVALHO, D. M. G.; PAULINO, M. F.; HATAMOTO-ZERVOUDAKIS, L. K.; OLIVEIRA, A. A.; KOSCHECK, J. F. W Suplementação infrequente e fontes protéicas para recria de bovinos em pastejo no período seco: parâmetros nutricionais. Revista Brasileira de Zootecnia, Viçosa, MG, v. 40, n. 4, p. 882-891, 2011.

PAULINO, M. F.; DETMANN, E.; VALADARES FILHO, S. C. Bovinocultura funcional nos trópicos. In: SIMPÓSIO DE PRODUÇÃO DE GADO DE CORTE - SIMCORTE, 6., Viçosa, 2008. Anais... Viçosa, MG: UFV, 2008. p. 89-111.

PAULINO, M. F.; ZAMPERLINI, B.; FIGUEIREDO, D. M.; MORAES, E. H. B. K.; FERNANDES, H. J.; PORTO, M. O.; SALES, M. F. L.; PAIXÃO, M. L.; ACEDO, T. S.; DETMANN, E.; VALADARES FILHO, S. C. Bovinocultura de precisão em pastagens. In: SIMPÓSIO DE PRODUÇÃO DE GADO DE CORTE SIMCORTE, 6., 2006, Viçosa, MG. Anais... Viçosa, MG: UFV, 2006. p. 133-154.
PILAU, A.; ROCHA, M. G.; SANTOS, D. T. Análise econômica de sistemas de produção para recria de bezerras de corte. Revista Brasileira de Zootecnia, Viçosa, MG, v. 32, n. 4, p. 966-976, 2003.

PORTO, M. O.; PAULINO, M. F.; VALADARES FILHO, S. C.; SALES, M. F. L.; LEÃO, M. I.; COUTO, V. R. M. Fontes suplementares de proteína para novilhos mestiços em recria em pastagens de capim-braquiária no período das águas: desempenho produtivo e econômico. Revista Brasileira de Zootecnia, Viçosa, MG, v. 38, n. 8, p. 1553-1560, 2009.

SANTOS, E. D. G.; PAULINO, M. F.; VALADARES FILHO, S. C.; LANA, R. P.; QUEIROZ, D. S.; FONSECA, D. M. Terminação de Tourinhos Limousin X Nelore em pastagem diferida de Brachiaria decumbens Stapf, durante a estação seca, alimentados com diferentes concentrados. Revista Brasileira de Zootecnia, Viçosa, MG, v. 33, n. 6, p. 1627-1637, 2004.

SILVA, D. J.; QUEIROZ, A. C. Análise de alimentos: métodos químicos e biológicos. 3. ed. Viçosa, MG: Universidade Federal de Viçosa, 2002. 165 p.

SILVA, R. R.; PRADO, I. N.; SILVA, F. F.; ALMEIDA, V. V. S.; SANTANA JÚNIOR, H. A.; QUEIROZ, A. C.; CARVALHO, G. G.P.; BARROSO, D. S. Comportamento ingestivo diurno de novilhos Nelore recebendo níveis crescentes de suplementação em pastejo de capimbraquiária. Revista Brasileira de Zootecnia, Viçosa, MG, v. 39, n. 9, p. 2073-2080, 2010.

SNIFFEN, C. J.; O'CONNOR, J. D.; VAN SOEST, P. J.; FOX, D. G.; RUSSELL, J. B. A net carbohydrate and protein system for evaluating cattle diets: II. Carbohydrate and protein availability. Journal of Animal Science, Champaign, v. 70, n. 11, p. 3562-3577, 1992.

UNIVERSIDADE FEDERAL DE VIÇOSA - UFV. SAEG - Sistema de análises estatísticas e genética. Viçosa, MG: UFV, 2001. 231 p. (Manual do usuário).

VALADARES FILHO, S. C.; PAULINO, P. V. R.; MAGALHÃES, K. A. Exigências nutricionais de zebuínos e tabela de composição de alimentos. BR-Corte. Viçosa, MG: Universidade Federal de Viçosa, 2006.

VAN SOEST, P. J. Nutritional ecology of the ruminant. 2. ed. Ithaca: Cornell University, 1994. p. 476.

VILLELA, S. D. J.; PAULINO, M. F.; VALADARES FILHO, S. C.; MARTINS, M. O.; ZAMPERLINI, B. Fontes de proteína em suplementos para bovinos em pastejo nos períodos da seca e de transição secaáguas. Revista Brasileira de Saúde e Produção Animal, Salvador, v. 10, n. 2, p. 266-277, abr./jun. 2009. 